\title{
FREEZE-DRIED PLATELET-RICH PLASMA PROMOTES TRIGEMINAL
NEUROPATHIC PAIN RELIEF IN A RAT MODEL
}

\section{ABSTRACT}

Objective: Neuropathic pain and treatment side effects decreasing quality of life, reducing productivity, and high costs due to long duration of treatment. Regenerative medicine is a new and effective alternative treatment for neuropathic pain, one of which is Platelet-Rich Plasma (PRP) therapy. The objective if this study is to prove that there are differences in neuroregeneration post-crush injury after FD-PRP administration.

Materials and Methods: Neuropathic pain model was made with crushing method, by compressing the infraorbital nerve using the artery clamp for 15 seconds. Rats divided into six groups. Each group was observed on day $14(\mathrm{~A}, \mathrm{~B}, \mathrm{C})$ and $21\left(\mathrm{~A}^{\prime}, \mathrm{B}^{\prime}, \mathrm{C}^{\prime}\right)$ to observe the macrophages, lymphocytes, and Schwann cells with Hematoxylin Eosin staining seen on horizontal plane of the infraorbital nerve with 400x magnification. Face grooming observations were performed on day 0 (A0, B0, C0), day 7 (A7, B7, C7), day 14 (A14, B14, C14), day 21 (A21, B21, C21).

Results: There were significant differences in face grooming frequencies between groups on day $0(\mathrm{p}=0.002)$. ANOVA Same Subject test on A', B', and C' revealed significant differences in macrophages and lymphocytes with score $0.02(\mathrm{p}-<0.05)$ and 0.013 (p0.05), respectively. There were significant differences between group $\mathrm{A}^{\prime}$ and $\mathrm{B}^{\prime}$ and between $\mathrm{B}^{\prime}$ and $\mathrm{C}^{\prime}(\mathrm{p}>0.05)$.

Conclusions: FD-PRP promotes nerve regeneration in axonotmesis, which was characterized by a decrease in face grooming frequency on day 7 and an increase in the number of lymphocytes, macrophages and Schwann cells on day 21 .

Keywords: Platelet-rich plasma, macrophages, lymphocytes, schwann cells, peripheral nerve injuries.

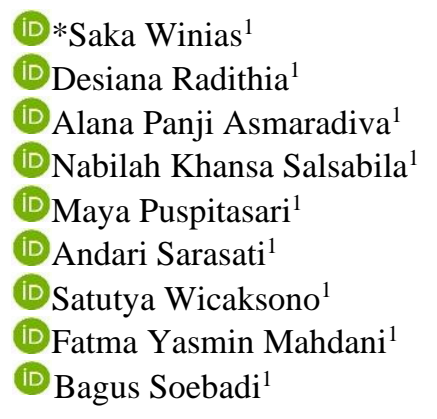

ORCID IDs of the authors:

S.W. $\quad$ 0000-0003-3039-0428

D.R. $\quad$ 0000-0003-2031-6283

A.P.A. $\quad 0000-0002-4564-2248$

N.K.S. $\quad$ 0000-0001-6075-964X

M.P. $\quad 0000-0002-5190-4670$

A.S. $\quad 0000-0003-4750-4620$

S.W. $\quad$ 0000-0002-4982-329X

F.Y.M. 0000-0001-8071-6639

B.S. $\quad 0000-0001-6919-418 X$
${ }^{1}$ Department of Oral Medicine, Faculty of Dental Medicine, Universitas Airlangga, Surabaya, Indonesia.

How to Cite: Winias S, Radithia D, Asmaradiva AP, Salsabila NK, Puspitasari M, Sarasati A, Wicaksono S, Mahdani FY, Soebadi B. Freeze-Dried Platelet-Rich Plasma Promotes Trigeminal Neuropathic Pain Relief in A Rat Model. Cumhuriyet Dent J 2020;23:4: 254-261.

*Corresponding Author:

Oral Medicine Specialist., Department of Oral Medicine, Faculty of Dental Medicine, Universitas Airlangga. Jl. Prof. Dr. Moestopo No. 47 Surabaya, East Java, Indonesia 60132.

Phone: +6231 $5030255 \quad$ Email: saka.winias@fkg.unair.ac.id 


\section{INTRODUCTION}

Lesions or somatosensory nervous system diseases cause neuropathic pain. Neuropathic pain that innervates the orofacial area can cause orofacial pain. Neuropathic pain can be caused by mechanical trauma or nerve compression due to surgery or neurological diseases such as postherpetic neuralgia, which causes functional and structural nerve disorders. The symptoms of neuropathic correlate to the failure of transmission of nerve impulses such as dysesthesia, hyperalgesia, allodynia, paresthesias, and others. Neuropathic pain is generally chronic, and it can decrease the patient's quality of life if not treated adequately. ${ }^{1}$

Pain sufferers have been treated with analgesics such as NSAIDs, anticonvulsants, antidepressants, and opioids. Surgical therapy is viable for neuropathic pain due to neurovascular compression, such as trigeminal neuralgia. Antiviral therapy is viable to cure pain-causing diseases such as post-herpetic neuralgia. Drugs and surgical therapy can relieve symptoms of neuropathic pain, but do not promote and accelerate the regeneration of damaged nerves. ${ }^{2}$ Various studies confirmed that nerve regeneration is the most effective and efficient therapy for neuropathic pain management; therefore, effective and efficient therapeutic methods for nerve regeneration is needed. ${ }^{3}$

Platelet-Rich Plasma (PRP) is a bioactive substance that is being developed for a variety of medical therapies due to high growth factor content in $\alpha$ platelet granules. A high concentration of growth factors such as Transforming Growth Factor- $\beta$ (TGF- $\beta$ ), platelet-derived growth factor (PDGF), vascular endothelial growth factor (VEGF), and insulin growth factor-1 (IGF-1) can accelerate inflammation and neuroregeneration processes. PRP has been commonly used in the therapy of musculoskeletal disease or injuries. ${ }^{4,5}$ Also, various studies have confirmed the PRP regenerative effect on injured nerves. However, there has been no study of the effect of FreezeDried PRP (FD-PRP) on injured nerves, particularly in axonotmesis. This study aimed to analyze the effects of FD-PRP on axonotmesis for neuropathic pain relief through cellular observation on lymphocytes, macrophages, Schwann cells, and facial grooming behavioral observation.

\section{MATERIALS AND METHODS}

This was a true experimental study with a post-test only control group design. This study received ethical approval by the Health Research Ethical Clearance Commission (HRECC) of the Faculty of Dental Medicine, Universitas Airlangga Number 140/HRECC.FODM/VII/2018. This study used a sample of Wistar rats (Rattus norvegicus), in which all samples were divided into 6 groups, namely the control group (A), crush injury treatment group (B), and crush injury treatment group + FD-PRP (C). Each group was observed on day 14 (A, B, C) and $21\left(\mathrm{~A}^{\prime}, \mathrm{B}^{\prime}, \mathrm{C}^{\prime}\right)$ to observe the macrophages, lymphocytes, and Schwann cells. A crush injury can cause clinically relevant axonotmesis lesions for certain larger-scale molecular and cellular nerve studies, and it is one of the pain indicators for face grooming observation in experimental animals. ${ }^{6,7}$ Face grooming observations were performed on day 0 (A0, B0, C0), day 7 (A7, B7, C7), day 14 (A14, B14, C14), day 21 (A21, B21, C21).

Allogeneic FD-PRP was obtained from the blood of 20 rats collected using a syringe containing dextrose citrate acid and centrifuged (Corelab BLC - 2012) for 10 minutes at $4000 \mathrm{rpm}$. The centrifugation separates the blood and plasma. The plasma was then transferred to another tube using a syringe. The plasma was centrifuged again for 10 minutes at $4000 \mathrm{rpm}$ to accumulate the PRP at the bottom of the tube. The obtained PRP was then sterilized using UV light before freeze-dried. The PRP was then frozen at $-83^{\circ} \mathrm{C}$ for 12 hours and lyophilized (Virtis Benchtop 4K 4BT4K2L-105) for 8 to 12 hours.

Rats in the treatment groups were anesthetized using ketamine per intraperitoneal and asepsized on the cheek region using $10 \%$ povidone-iodine. Then surgery was performed to access the infraorbital nerve fibers, which were then crushed for 15 seconds using artery clamp. The wound was then sutured and asepsized using povidone-iodine $10 \%$. 
The FD-PRP was dissolved in carboxymethylcellulose (CMC-Na 1\%) with a 1:1 ratio and applied using an $18 \mathrm{G}$ syringe on the treatment groups 24 hours after the crushing.

Face grooming observation was performed by transferring the experimental animal to a smaller cage without base with a mirror facing the camera for video recording. The recordings were 10minute videos and recorded between $07.00-18.00$. Three independent observers examined the video recordings, and the mean was obtained. The face grooming frequency was counted if the front legs of the experimental animal reach the treated region without body grooming after (isolated face grooming).

The macrophages, lymphocytes, and Schwann cells were calculated once the experimental animal anesthetized. The HPA of the infraorbital nerve was obtained from Hematoxylin Eosin (HE) staining. The calculation was performed using a light microscope (Nikon Eclipse e200) with 400x magnification.

\section{RESULTS}

In general, we found that macrophages, lymphocytes and schwann cell increased in PRP administration group. The highest face grooming frequency was observed in $\mathrm{B} 0$, and the face grooming frequencies of all groups tended to decrease. However, an increase in face grooming frequency was observed in group A21 and group B14. (Figure 1)

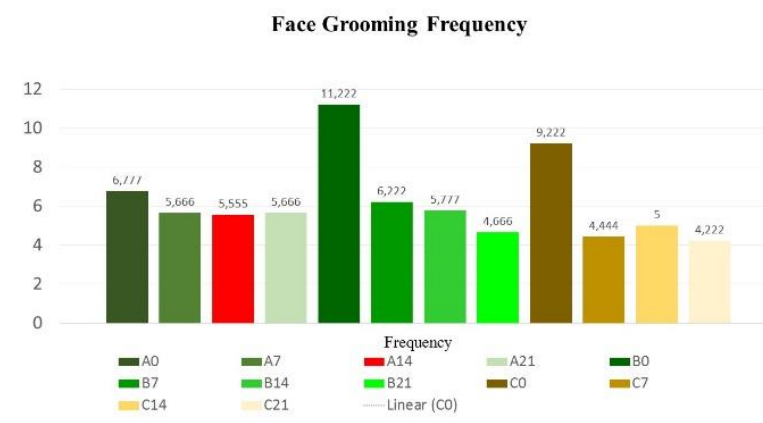

Figure 1 : Face Grooming Frequency Chart

There was a significant difference in face grooming frequency between groups B and C, and there was no significant frequency observed in group A. (Table.1)

Table 1. The Repeated-Measures ANOVA in Face Grooming between Groups

\begin{tabular}{cc}
\hline Group & Sig. \\
\hline A & 0.190 \\
B & $0.000^{*}$ \\
C & $0.000^{*}$ \\
\hline
\end{tabular}

*significantly difference

There were significant differences in face no significant differences in face grooming grooming frequencies between groups on day $0(\mathrm{p}$ frequencies between groups. (Table. 2)

$=0.002$ ). Whereas on day 7,14 , and 21, there were

Table 2. The One-Way ANOVA in Face Grooming between Days

\begin{tabular}{cc}
\hline Time of Inspection & Sig. \\
\hline $\mathbf{0}$ & $0.002^{*}$ \\
$\mathbf{7}$ & 0.212 \\
$\mathbf{1 4}$ & 0.751 \\
$\mathbf{2 1}$ & 0.356 \\
\hline
\end{tabular}

*significantly difference

There was an increase observed in lymphocytes, macrophages, and Schwann cells from day 14 to day 21 in each group. The number of lymphocytes and macrophages significantly increased in the treatment groups, while the number of Schwann cells significantly increased in control positive groups. (Figure 2)

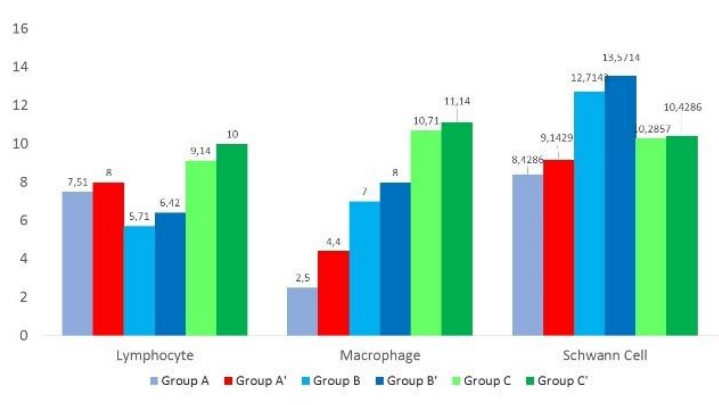

Figure 2 : Mean of Lymphocyte, Macrophage and Schwann Cells 
Lymphocytes appeared round shape and almost filled with dark nuclei, macrophages can be found in several forms, commonly foun in oval shape with light-colored cytoplasm and dark nucleus, and Schwann cells are cells around axons, have a single nucleus, and form myelin sheaths. They were observed using a light microscope at 400x magnification. The cells distribution in day 14 and day 21 were presented in Figure 3.
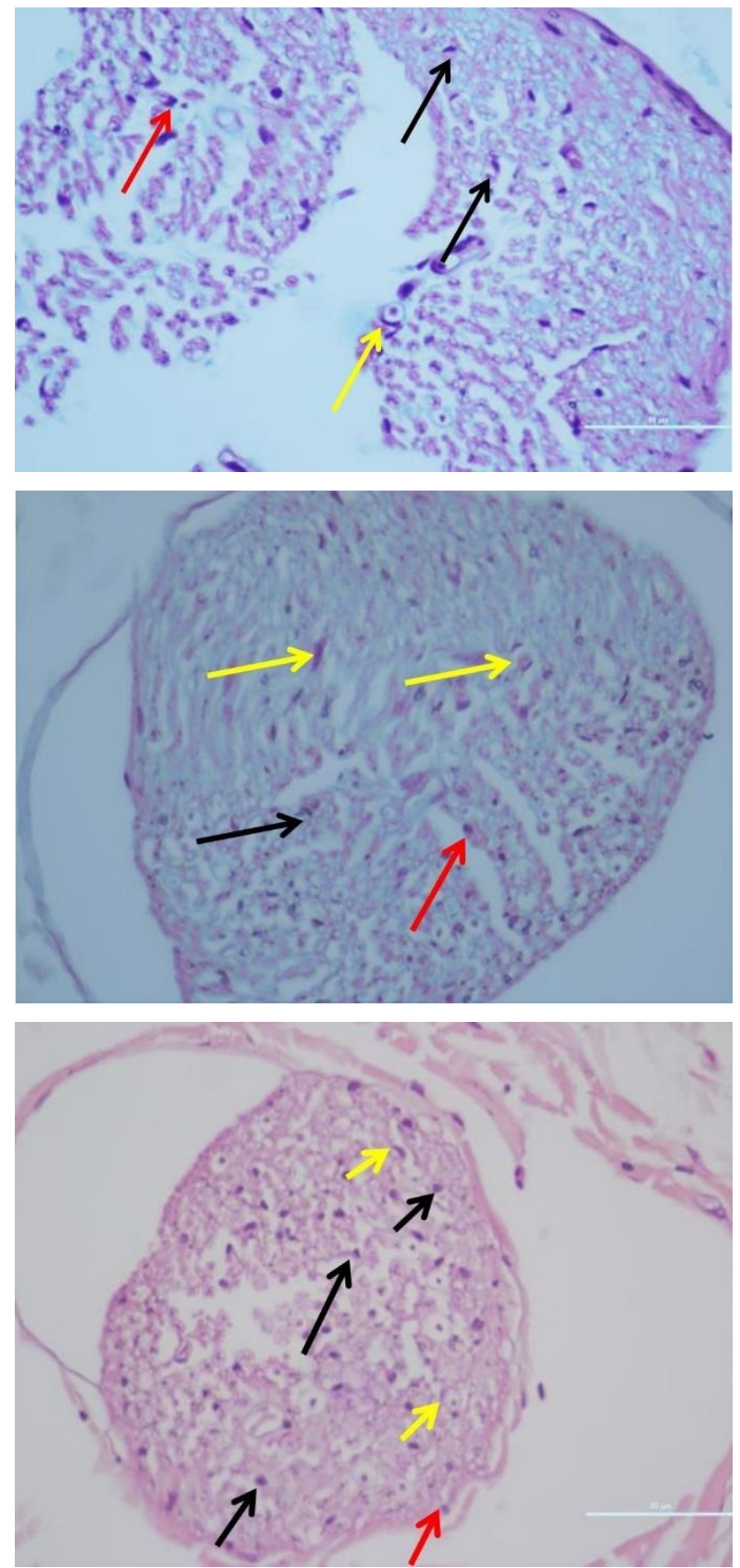
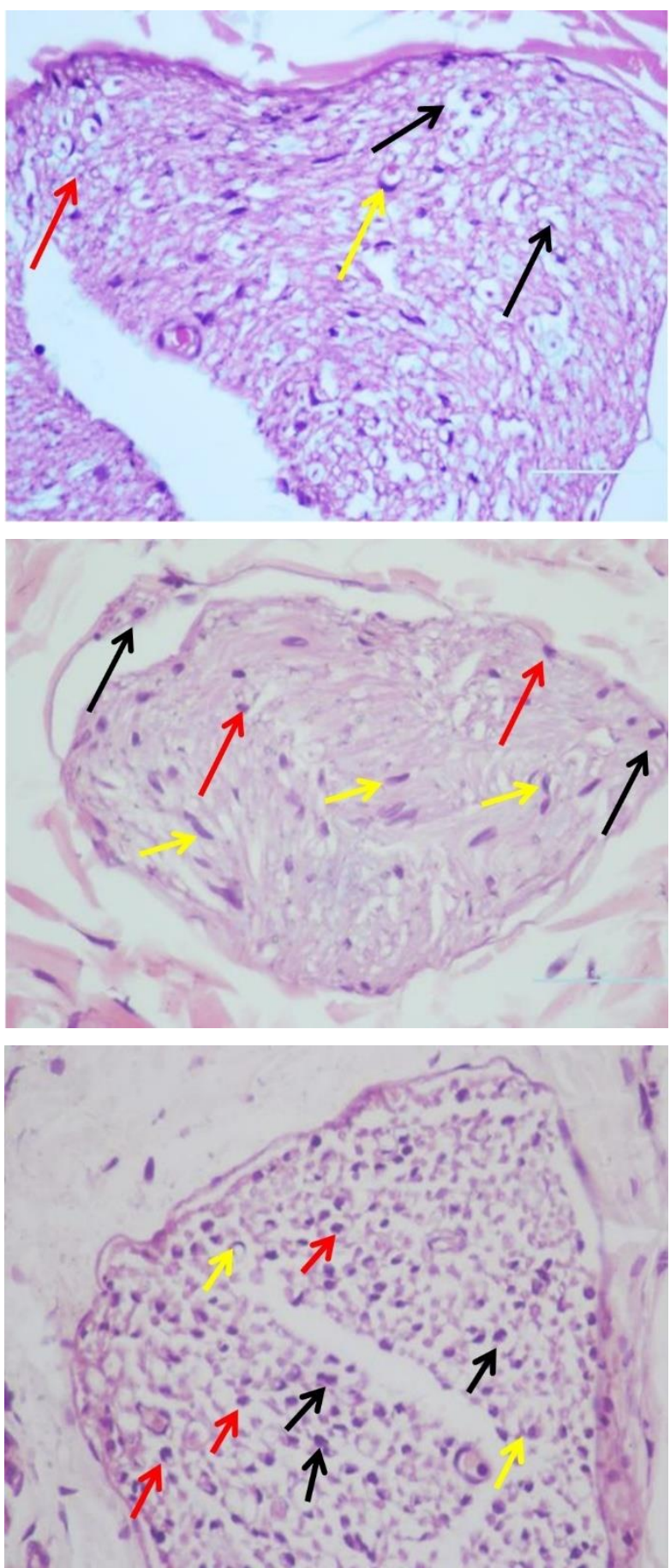

Figure 3 : Inflammation cells and Schwann cells under light microscope with 400x magnification on groups A, A', B, B', $\mathrm{C}$, and $\mathrm{C}^{\prime}$. Red arrow points lymphocytes cells, black arrow points macrophages cells and yellow arrow points Schwann cells.

ANOVA test was carried out on day 14 and 21 to observe the number of Schwann cells, macrophage cells, and lymphocyte cells. ANOVA test results on day 14 are presented in Table 3, on day 21 are presented in Table 4 and Independent ttest of each cells presented on Table 5 . 
Table 3. Statistical analysis data relating to the quantity of Macrophages, lymphocytes and schwanncells in each treatment group on day 14.

\begin{tabular}{|c|c|c|c|c|c|c|}
\hline & \multirow{2}{*}{ Group } & \multirow{2}{*}{$\operatorname{Mean} \pm$ SD } & \multirow{2}{*}{$\begin{array}{c}\text { One-way } \\
\text { ANOVA test }\end{array}$} & \multicolumn{3}{|c|}{ LSD test } \\
\hline & & & & $\mathrm{A}$ & $\mathrm{B}$ & $\mathrm{C}$ \\
\hline \multirow{4}{*}{ Macrophages } & $\mathrm{A}$ & $7.00 \pm 0.816$ & \multirow{3}{*}{0.000} & - & $0.007 *$ & $0.000 *$ \\
\hline & B & $5.43 \pm 0.976$ & & - & - & $0.000 *$ \\
\hline & $\mathrm{C}$ & $10.71 \pm 1.113$ & & - & - & - \\
\hline & A & $5.71 \pm 0.488$ & \multirow{3}{*}{0.000} & - & $0.001 *$ & $0.000 *$ \\
\hline \multirow[t]{2}{*}{ Lymphocytes } & B & $7.57 \pm 0.976$ & & - & - & $0.004 *$ \\
\hline & $\mathrm{C}$ & $9.14 \pm 1.069$ & & - & - & - \\
\hline \multirow{3}{*}{ Schwann cells } & A & $8.42 \pm 1.272$ & \multirow{3}{*}{0.000} & - & $0.000 *$ & $0.006^{*}$ \\
\hline & B & $12.71 \pm 1.113$ & & - & - & $0.001 *$ \\
\hline & $\mathrm{C}$ & $10.28 \pm 0.951$ & & - & - & - \\
\hline
\end{tabular}

* = there is a significant difference $(\mathrm{p}<0.05)$

Table 4. Statistical analysis data relating to the quantity of Macrophages, lymphocytes and schwann cells in each treatment group on day 21.

\begin{tabular}{|c|c|c|c|c|c|c|}
\hline & \multirow{2}{*}{ Group } & \multirow{2}{*}{ Mean \pm SD } & \multirow{2}{*}{$\begin{array}{c}\text { One-way } \\
\text { ANOVA test }\end{array}$} & \multicolumn{3}{|c|}{ LSD test } \\
\hline & & & & $A^{\prime}$ & $\mathrm{B}^{\prime}$ & $\mathrm{C}^{\prime}$ \\
\hline \multirow{4}{*}{ Lymphocytes } & $A^{\prime}$ & $6.43 \pm 0.976$ & & - & $0.012^{*}$ & $0.000 *$ \\
\hline & $\mathrm{B}^{\prime}$ & $8.00 \pm 1.00$ & 0.000 & - & - & $0.002 *$ \\
\hline & $\mathrm{C}^{\prime}$ & $10.00 \pm 1.155$ & & - & - & - \\
\hline & $A^{\prime}$ & $8.00 \pm 0.816$ & & - & $0.048^{*}$ & $0.000 *$ \\
\hline \multirow[t]{3}{*}{ Macrophages } & $\mathrm{B}^{\prime}$ & $6.57 \pm 0.976$ & 0.000 & - & - & $0.000 *$ \\
\hline & $\mathrm{C}^{\prime}$ & $11.14 \pm 1.773$ & & - & - & - \\
\hline & $A^{\prime}$ & $9.14 \pm 1.09$ & & - & $0.000 *$ & 0.098 \\
\hline \multirow[t]{2}{*}{ Schwann cells } & $\mathrm{B}^{\prime}$ & $13.57 \pm 1.272$ & 0.000 & - & - & $0.000 *$ \\
\hline & $\mathrm{C}^{\prime}$ & $10.43 \pm 1.718$ & & - & - & - \\
\hline
\end{tabular}

Table 5. Independent T-Test on day 14 and 21

\begin{tabular}{cc}
\hline Parameter & Sig. \\
\hline Lymphocyte & 0.205 \\
Macrophages & $0.049^{*}$ \\
Schwann & 0.433 \\
\hline
\end{tabular}

\section{DISCUSSION}

The PRP effect on neuroregeneration was observed through face grooming frequency observation and histopathological examination by calculating the number of macrophages, lymphocytes, and Schwann cells. Face grooming frequency was expected to illustrate the effect of FD-PRP on pain arising from nerve injury, and the number of macrophages, lymphocytes, and Schwann cells was expected to demonstrate the effect of FD-PRP on neuroregeneration, increasing the inflammatory response efficiency and promoting Schwann cells proliferation for myelin sheath formation.

The face grooming frequencies of $\mathrm{A} 0, \mathrm{~A} 7$, A14, and A21 were close, indicating that face grooming was not influenced by external factors such as stress and de-arousal conditions. Therefore, group A was the comparison for group B and C in face grooming observation. There were significant differences between group A0, B0, and $\mathrm{C} 0$. It indicated that crush injury influenced face grooming frequency, which is the response of experimental animals to pain arising from crushinjury treatment. Wound healing and neuroregeneration, as observed in group B and C, influenced the face grooming frequency. ${ }^{9}$

Two hours after FD-PRP injection, the face grooming frequency of group $\mathrm{C} 0$ was lower than $\mathrm{B} 0$. This suggested that FD-PRP affected face grooming frequency by accelerating the neuroregeneration process, as observed in group $\mathrm{C} 0 .{ }^{10}$

Comparison test results of day 0 revealed significant differences in face grooming frequency, while on day 7,14 , and 21 , there was no significant 
difference, indicating the wound healing process and relief of pain, therefore decreasing the face grooming frequency. ${ }^{11}$ The insignificant result was related to the animals' responses to the given treatment. ${ }^{12,13}$

This study also examined the effect of FD-PRP on neuroregeneration acceleration by calculating the cells involved, namely lymphocyte, macrophages and Schwann cells. Lymphocytes, macrophages and Schwann cells play an important role in inflammation response due to injury. Inflammation promotes an adequate microenvironment in supporting the neuroregeneration process. These cells release various kinds of cytokines, chemokines, and neurotrophic factors to synergistically accelerate neuroregeneration.

Lymphocytes cells revealed significant difference each group $(\mathrm{p}<0.05)$. This study in line with Yun et al., (2011) found that one of growth factor which contained in PRP called TGF- $\beta$. This growth factor play an important role for lymphocytes proliferation. When PRP was given to injured nerve, the number of inflammatory cells including lymphocytes increased to accelerate neuroregeneration. ${ }^{14}$

The macrophages cells calculation showed a significant result $(\mathrm{p}=0.000, \mathrm{p}<0.05)$. Macrophages in group A made up 9\% of cells in normal peripheral nerves, while group $B$ showed a greater number of macrophages compared to group $\mathrm{A}$. This was caused by macrophage migration activated by Schwann cells and local macrophages for clearing out myelin debris. ${ }^{15}$ There was a significant improvement in group $\mathrm{C}$ due to growth factors contained in FD-PRP, one of which was PDGF in increasing macrophage migration. An increase in the number of macrophages indicates faster healing. Macrophage dysfunction or a decrease in the number of macrophages inhibits the angiogenesis process, which eventually slows the healing process. ${ }^{16}$

There were significant differences between group $(\mathrm{p}<0.05)$. The significant differences were due to the increased number of Schwann cells in Wallerian degeneration. The number of Schwann cells post-injury increased because of increasing of macrophages cells for clearing out cellular debris and myelin. In successful nerve regeneration, clearing out of cellular and myelin debris by Schwann cells and macrophages completes in 21 to 42 days. $^{16}$

The significant difference on day 21 between group $\mathrm{B}^{\prime}$ and $\mathrm{C}^{\prime}$ indicated that FD-PRP treatment on group $\mathrm{C}^{\prime}$ had accelerated the resolution of inflammation as the Wallerian degeneration was quickly initiated by the contained growth factors. ${ }^{17}$

The non-significant difference on day 21 between group $\mathrm{A}^{\prime}$ and $\mathrm{C}^{\prime}$ indicated that the neuroregeneration in group $\mathrm{C}^{\prime}$ was initiated early by the growth factors; therefore, the number of Schwann cells was not significant to the group A'. These growth factors, including transforming growth factor (TGF- $\beta 1$ ), vascular endothelial growth factor (VEGF), and insulin-like growth factor (IGF- I) contained in FD-PRP, improve the inflammatory mediators' efficiency and accelerate the neuroregeneration processes. TGF- $\beta 2$ and TGF- $\beta 3$ also play an important role in Schwann cell proliferation and differentiation. ${ }^{18}$

Lymphocytes revealed no significant differences between day 14 and day 21. During inflammation, $\mathrm{T}$ lymphocytes are activated and release cytokines, which activate macrophages and thereby release more cytokines. Lymphocytes and macrophages interact in a bidirectional pathway, and their interactions play an important role in chronic inflammation; therefore, the number of lymphocytes was not significantly different. ${ }^{19}$

Independent $\mathrm{T}$-Test compared between variables of day 14 and 21, and it showed that there was a significant difference in macrophage $(p=0.049)$. This was because the healing process of chronically inflamed injured tissue consumes time; therefore, the number of macrophages for clearing out debris remained high. ${ }^{20}$

Independent T-test compared on Schwann cells revealed no significant differences between groups. This was because (1) sprouting axons grow on day 3 to 42 post-injury, and the Schwann cells proliferation and axons and myelin debris clearance by macrophages completes on day 21 to 42 after injury for successful regeneration ${ }^{16,21,22}$ 
and (2) tissue vascularization, denervation of chronic Schwann cells, endoneurial and perineural fibrosis, axons inability to reach the correct target neuron, the distance for axons to reach the target neuron, cell atrophy, the rate of nerve regeneration, and other factors influencing the neuroregeneration. ${ }^{23-26}$

\section{CONCLUSIONS}

FD-PRP increase lymphocytes, macrophages alnd scwhann cells proliferation, that accelerate peripheral nerve regeneration. These cells initiate several neurotrophic factors to achieve fast recovery. Thus, this study concluded that FD-PRP promotes nerve regeneration in axonotmesis injury, which was characterized by a decrease in face grooming frequency on day 7 and an increase in the number of lymphocytes, macrophages and Schwann cells on day 21 .

\section{ACKNOWLEDGEMENT}

The authors would like to thank the Stem Cell Center and Tissue Bank of Dr. Soetomo Hospital, Surabaya for its support. This research is financially supported by Faculty of Dental Medicine Universitas Airlangga [grant numbers 1408/UN3/2019].

\section{CONFLICT OF INTEREST}

The authors declare no conflict of interest.

\section{REFERENCES}

1. Jensen, T.S., Baron, R., Haanpää, M., Kalso, E., Loeser, J.D., Rice, A.S.C. and Treede, R.D. (2011), “A new definition of neuropathic pain", Pain, International Association for the Study of Pain, Vol. 152 No. 10, pp. 2204-2205.

2. Obata, H. (2017). Analgesic Mechanisms of Antidepressants for Neuropathic Pain. International Journal of Molecular Sciences, 18(2483), pp. 1-12.

3. Xie, W., Strong, J. and Zhang, J. (2017). Active Nerve Regeneration with Failed Target Reinnervation Drives Persistent Neuropathic Pain. Eneuro, 4(1), pp. 116.2017 .

4. Oudelaar, B., Peerbooms, J., Huis in 't Veld, R. and Vochteloo, A. (2018). Concentrations of Blood Components in Commercial Platelet-Rich Plasma Separation Systems: A Review of the Literature. The American Journal of Sports Medicine, 47(2), pp. 1-8.
5. Kawase, T. (2015). Platelet-rich plasma and its derivatives as promising bioactive materials for regenerative medicine: basic principles and concepts underlying recent advances. Odontology, Springer Japan, 103(2), pp. 126-135.

6. Menorca, R.M.G., Fussel, T.S., Elfar, J.C., 2015. Peripheral Nerve Trauma: Mechanisms of Injury and Recovery. Hand Clin. Author Manuscr. 29, 317-330.

7. Romero-reyes, M., Akerman, S., Nguyen, E., Vijjeswarapu, A., Hom, B., Dong, H., Charles, A.C., 2012. Spontaneous Behavioral Responses in the Orofacial Region: A Model of Trigeminal Pain in Mouse. Am. Headache Soc. Res. 5010, 137-151.

8. Deseure, K., Hans, G.H., 2015. Chronic Constriction Injury of the Rat's Infraorbital Nerve (IoN-CCI) to Study Trigeminal Neuropathic Pain. J. Vis. Exp. 1-6.

9. Kalueff A V, Stewart A M, Song C, Berridge K C, Graybiel A M, Fentress J C. 2016. Neurobiology of Rodent Self-Grooming and Its Value for Translational Neuroscience. Nat Rev Neurosci. 17(1): 45-59.

10.Xu, M., Aita, M., Charles, C., 2008. Partial infraorbital nerve ligation as a model of trigeminal nerve injury in the mouse: Behavioral, Neural and Glial reactions. J. Pain 9, 1036-1048.

11. Alvites, R, Caseiro A R, Pedrosa S S, Branquinho M V, Ronchi G, Geuna S, Varejao A S P, Mauricio A C. 2018. Peripheral Nerve Injury and Axonotmesis: State of The Art and Recent Advances. Cogent Medicine. p.8.

12. Souza, I., Vasconcelos, A G C., Caumo, W., Baptista, A F. 2017. Resilience Profile of Patients with Chronic Pain. Cad. Saúde Pública, 33(1):e00146915.

13. Yeung, E W., Zautra, A., Arewasikporn, A. 2012. Resilience and Chronic Pain. Journal of Social and Clinical Psychology, Vol. 31, No. 6, pp. 593-617.

14. Yu, W., Wang, J. and Yin, J. Platelet-rich plasma: A promising product for treatment of peripheral nerve regeneration after nerve injury. 2011. International Journal of Neuroscience, Vol. 121 No. 4, pp. 176-180.

15. W. Daly1, L. Yao1, D. Zeugolis1, A. Windebank2 and A. Pandit. A biomaterials approach to peripheral nerve regeneration: bridging the peripheral nerve gap and enhancing functional recovery. 2011. J. R. Soc. Interface. $2: 452$. 
16. Geuna, S., Raimondo, S., Ronchi, G., Di Scipio, F., Tos, P., Czaja, K. and Fornaro, M. (2009), Chapter 3 Histology of the Peripheral Nerve and Changes Occurring During Nerve Regeneration, International Review of Neurobiology, 1st ed., Vol. 87, Elsevier Inc., 87003-7.

17. Kuffler, Damien P. 2013. Platelet-Rich Plasma and the Elimination of Neuropathic Pain. Molecular Neurobiology. p. 1-18.

18. Sánchez, Mikel., Garate, Ane., Delgado, Diego., Padilla, Sabino. 2017. Platelet-Rich Plasma, an Adjuvant Biological Therapy to Assist Peripheral Nerve Repair. Neural Regeneration Research Journal. Vol.12(1). p.47-52.

19. Kumar, V., Abbas, abul K. and Aster, J.C. (2013), Basic Pathology, Journal of Clinical Pathology, Vol. 47.

20. Mahadewa, Tjokorda Gde Bgus. 2013. Saraf Perifer Masalah dan Penanganannya. Permata Puri Media: Jakarta Barat.

21. Czaja, K., Burns, G. A., and Ritter, R. C. 2008. Capsaicin-Induced Neuronal Death and Proliferation of The Primary Sensory Neurons Located in The Nodose Ganglia of Adult Rats. Neuroscience. Vol.154. p.621630 .
22. Su, H.X., Cho, E.Y. 2003. Sprouting of Axon-like Processes from Axotomized Retinal Ganglion Cells Induced by Normal and Preinjured Intravitreal Optic Nerve Grafts. Brain Research. Vol.991. p.150-162.

23. Painter, M.W., Brosius, Lutz A., Cheng, Y.C., Latremoliere, A., Duong, K., Miller, C.M., Posada, S., Cobos, E.J., Zhang, A.X., Wagers, A.J., Havton, L.A., Barres, B., Omura, T., Woolf, C.J. 2014. Diminished Schwann Cell Repair Responses Underlie AgeAssociated Impaired Axonal Regeneration. Neuron. Vol. 83. p.331-343.

24. Scheib J, Hoke A. 2013. Advances in Peripheral Nerve Regeneration. Nature Reviews Neurology. Vol.9. p.668-676.

25. Zochodne DW. 2012. The Challenges and Beauty of Peripheral Nerve Regrowth. Journal of Peripheral Nervous System. Vol. 17. p.1-187.

26.Winias S, Radithia D,Parmadiati AE, Soebadi B, Ernawati DS, Hadi P, Soesilowati R. 2020. Allogenous Freeze-Dried Platelet-Rich Plasma Promotes Peripheral Myelin Repair in Chronic Constriction Nerve Injury . Sys Rev Pharm. Vol 11(6). p 254-248. 